\title{
Rapidly changing mortality profiles in South Africa in its nine provinces
}

The Second National Burden of Disease Study ${ }^{[1,2]}$ has confronted the data-quality issues associated with vital registration of cause of death $^{[3-5]}$ and derived updated estimates of the levels and causes of mortality for 1997 - 2012 for 140 specific causes, 23 categories and four broad cause groups ${ }^{[6]}$ Estimates have been produced by age, sex, province and population group, providing unparalleled information about disease trends and health disparities in the country.

Our results show a number of successes where the health of the population has improved ${ }^{[1]}$ HIV/AIDS deaths dropped from just over 306000 in 2006 to 154000 in 2012 (Fig. 1). This decline in the number of deaths corresponds with the rollout of antiretroviral treatment. Even with these gains, HIV/AIDS is still the single leading cause of death in South Africa (SA), and the prevention of the spread of HIV and the provision of access to treatment are of paramount importance.

The study also highlights the fact that there are a considerable number of deaths from non-communicable diseases, exceeding the number from HIV/AIDS and tuberculosis combined by 2012. ${ }^{[1]}$ Cardiovascular conditions including stroke, ischaemic heart disease and hypertensive heart disease constitute the leading category of non-communicable disease deaths in SA. However, different trends in cause-specific non-communicable diseases were observed; for example, tobacco-related mortality has declined, while deaths from diabetes and renal disease have increased. ${ }^{[1,7]}$ Furthermore, injury deaths have declined since the late 1990 s, with a $52 \%$ decrease in agestandardised death rates between 1997 and 2012. ${ }^{[1]}$

Interestingly, the top ten single causes of death have not changed over the 16-year period, and include causes from all four broad cause groupings, i.e. HIV/AIDS and tuberculosis, other type 1 conditions (other communicable diseases, maternal causes, perinatal conditions and nutritional deficiencies), non-communicable diseases and injuries. ${ }^{[1]}$ Although the proportions and rankings of the top causes have shifted, this finding reflects a continuing quadruple burden that has characterised the disease profile in SA since the late 1990 s. ${ }^{[8]}$

In addition to cause-of-death information, national and provincial reports can be found at http://www.mrc.ac.za/bod/reports.htm and provide trends in four key demographic indicators that reflect the status of development and health. Estimates of the infant mortality rate, the under-five mortality rate, the adult mortality rate (the probability of a 15-year-old dying before reaching 60 years) and life expectancy at birth are provided for the years 2000, 2005, 2010 and

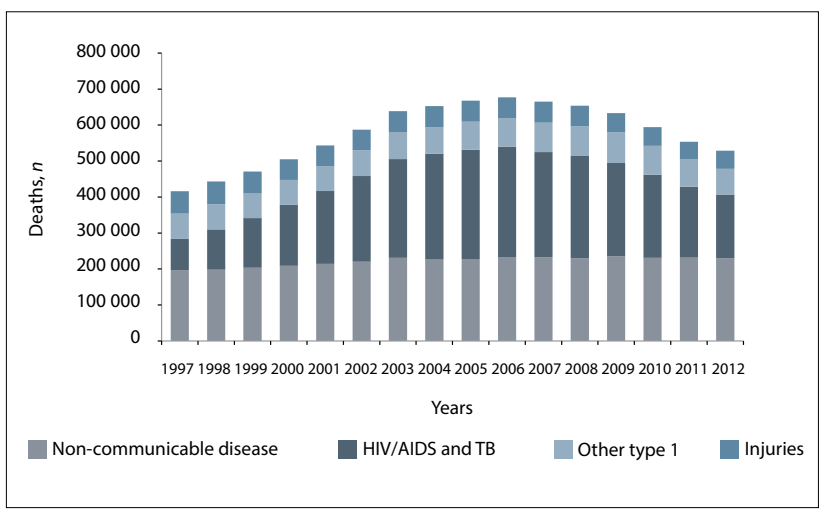

Fig. 1. Number of deaths by broad cause group, 1997 - 2012.
2012. The infant mortality rate, under-five mortality rate and adult mortality rate decreased between 2005 and 2012, and life expectancy at birth increased from 2005 onwards, consistent with the trends obtained from the Rapid Mortality Surveillance system established by the South African Medical Research Council. ${ }^{[9]}$

Our study measured premature mortality by counting the years of life lost depending on the age at which a death occurs compared with a standard life expectancy, and estimated over 10 million years of life lost due to premature mortality in 2012. Much of this premature loss of life can be avoided if appropriate action is taken, and the different provincial profiles of the causes of premature mortality should be used to guide strategies to improve health in each province. The leading causes of premature mortality for Gauteng and Limpopo provinces are shown in Fig. 2 to illustrate that while HIV/AIDS dominates as the leading cause, Gauteng Province needs to emphasise intersectoral actions in order to address the mortality of young people due to interpersonal violence, and Limpopo needs to focus on improving the quality of care in health services and access to water and sanitation by communities to address the preventable burden from infectious diseases.

Our study has produced a wealth of information that warrants further exploration and interpretation, within acknowledged limitations related to the sources of data and methodologies. ${ }^{[1]}$ The Burden of Disease Research Unit invites researchers and experts

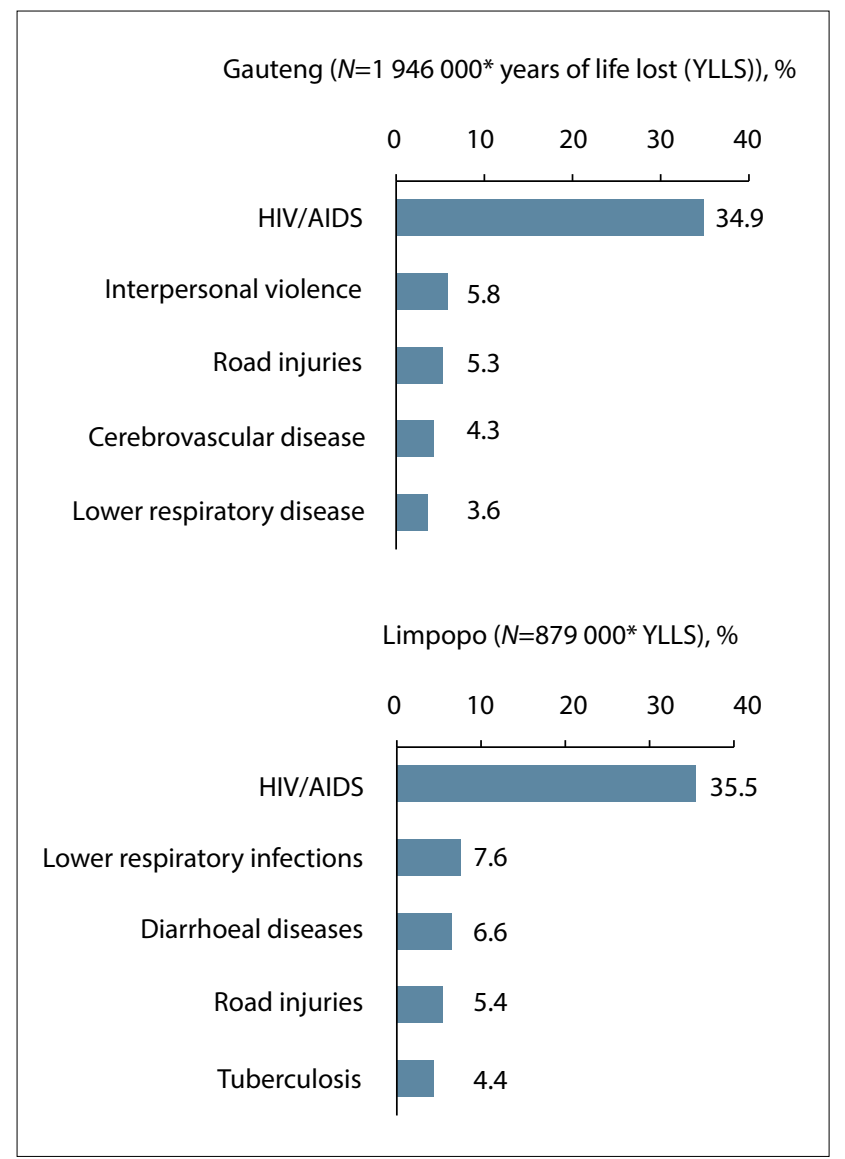

Fig. 2. Top five causes of premature mortality for selected provinces, 2012. ( ${ }^{*}$ Note: Numbers rounded to the nearest thousands.) 
interested in collaborating on further investigations to contact Dr Victoria Pillay-van Wyk.

Acknowledgements. We thank Statistics South Africa for providing causeof-death data; the Second National Burden of Disease Study team including William Msemburi, Ria Laubscher, Pam Groenewald, Beatrice Nojilana, Jané D Joubert, Richard Matzopoulos, Megan Prinsloo, Nadine Nannan, Theo Vos, Nontuthuzelo Somdyala, Nomfuneko Sithole, Ian Neethling, and Edward Nicol for generation and review of estimates; and Elize de Kock, Sulaiman Abrahams, Claudette Garnie and Monique Fourie for administrative support. This research and the publication thereof were partly funded by the South African Medical Research Council's Flagships Awards Project (SAMRC-RFA-IFSP-01-2013/SA CRA 2).

\section{Pillay-van Wyk}

Burden of Disease Research Unit, South African Medical Research Council, Cape Town, South Africa victoria.pillayvanwyk@mrc.ac.za

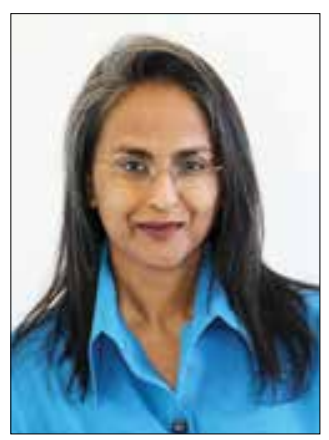

\section{R E Dorrington}

Centre for Actuarial Research, Faculty of Commerce,

University of Cape Town, South Africa

\section{Bradshaw}

Burden of Disease Research Unit, South African Medical Research

Council, Cape Town, South Africa

1. Pillay-van Wyk V, Msemburi W, Laubscher R, et al. Mortality trends and differentials in South Africa from 1997 to 2012: Second National Burden of Disease Study. Lancet Glob Health 2016;4:e642-653. http://dx.doi.org/10.1016/S2214-109X(16)30113-9

2. Msemburi W, Pillay-van Wyk V, Dorrington RE, et al. Second national burden of disease study for South Africa: Cause-of-death profile for South Africa, 1997 - 2012. Cape Town: South African Medical Research Council, 2016. http://www.mrc.ac.za/bod/SouthAfrica2012.pdf (accessed 21 December 2016).

3. Joubert J, Rao C, Bradshaw D, Vos T, Lopez AD. Evaluating the quality of national mortality 3. Joubert J, Rao C, Bradshaw D,
statistics from civil registration in South Africa, 1997 - 2007. PLoS One 2013;8:e64592. http://dx.doi. org/10.1371/journal.pone.0064592

4. Pillay-van Wyk V, Bradshaw D, Groenewald P, Laubscher R. Improving the quality of medical certification of cause of death: The time is now! S Afr Med J 2011;101:626. http://dx.doi.org/10.7196/ SAMJ.5047

5. Bradshaw D, Msemburi W, Dorrington R, Pillay-van Wyk V, Laubscher R, Groenewald P, for the South African National Burden of Disease team. HIV/AIDS in South Africa: How many people died from the disease between 1997 and 2010? AIDS 2016;30:771-778. http://dx.doi.org/10.1097/ QAD .0000000000000947

6. Pillay-Van Wyk V, Laubscher R, Msemburi W, et al. Second South African National Burden of Disease Study: Data cleaning, validation and SANBD list. Cape Town: Medical Research Council, 2014. http:// www.mrc.ac.za/bod/SANBDReport.pdf (accessed 21 December 2016).

7. Nojilana B, Bradshaw D, Pillay-van Wyk V, et al. Emerging trends in non-communicable disease mortality in South Africa, 1997 - 2010. S Afr Med J 2016;106(5):477-484. http://dx.doi.org/10.7196/ SAMJ.2016.v106i4.10674

8. Bradshaw D, Groenewald P, Laubscher R, et al. Initial burden of disease estimates for South Africa, 2000. S Afr Med J 2003;93:682-688.

9. Dorrington RE, Bradshaw D, Laubscher R, Nannan N. Rapid mortality surveillance report 2015. Cape Town: South African Medical Research Council, 2016. http://www.mrc.ac.za/bod/ RapidMortalitySurveillanceReport2015.pdf (accessed 21 December 2016).

S Afr Med J 2017;107(3):168-169. DOI:10.7196/SAMJ.2017.v107i3.12344 